\title{
When Not to Look at the Sky?
}

\author{
Vince Gaffiney \\ University of Bradford, UK \\ V.Gaffney@bradford.ac.uk
}

\begin{abstract}
Thanks to the peerless stars
ablaze in the very depths of the sky,

my consumed eyes see

only memories of suns.
\end{abstract}

- from "Laments of an Icarus" by Charles Baudelaire, 1861

(trans. P. Gaffney, from Baudelaire 2006 [1861])

The following notes are both personal and partial. This should not be such a surprise as I shall draw, shamelessly, upon my experience of being taught, carrying out fieldwork and undertaking research - although I will not dwell, as such, upon the substance of those activities. Any observations that I derive from such encounters may have as much, or as little, relevance as the reader may wish to take from them. Initially, such reflections spring from the position that my recent career has increasingly required an archaeological appreciation of the firmament. This has been an interesting development, given that for much of my time as a landscape archaeologist, whether in the field or in a classroom, I have largely avoided looking at the sky. To appreciate why that should have been so requires some understanding of the time in which I emerged with an archaeological degree, from Reading, in 1980. For most archaeologists, this was a period in which the discipline was largely presented as a matter of chronology, culture and periodisation. As one of my tutors, Richard Bradley, once noted in a comment on temporality in archaeology, our world view was much like the history I was taught at school, and just "one thing after the other" (Bradley 1998, 87)!

This is not to say that I was unaware of the potential significance of things skywards. The physical manifestations of astronomic alignments of great monuments, such as Stonehenge or Newgrange, were reasonably well appreciated, as was the large, and readily available, ethnographic literature on related subjects. However, as an archaeologist teetering on the first rung of a career, there was also a general feeling that such issues were not for the likes of me! To an extent this position was a consequence of the apparent technical barriers to such studies, but also the attitudes of an arts discipline that 
was still focused, intently, on the contents of the rubbish pit. Contemporary debates in archaeoastronomy, for example in respect of Alexander Thom's work, were, for many, a cautionary tale against engaging with such matters, rather than an inspiration to act or an insight into the potential of such research (MacKie 1974). Consequently, my position of relative ignorance was not actually perceived as a terrible thing in a young archaeologist who was, in any case, fated to spend several years sieving topsoil on the Berkshire Downs and pondering, generally, on the nature of artefact scatters on chalk landscapes.

At a personal level, two linked events paved the way for an emergent interest in the sky and these may still be relevant to how we view such studies today. After a brief period in museums in the early 80 s, spent sheltering from the impacts of Tory restructuring on archaeology, I decided to move to former Yugoslavia, to collect data for a PhD centred on the island of Hvar. The striking limestone scenery of central Dalmatia contrasted, dramatically, with the comfortable chalk landscapes of Dorset, Wiltshire and Berkshire with which I was most familiar. The visual connectivity of archaeological sites on the Croatian islands, often positioned high on limestone scarps or set on island promontories, hammered home the symbiotic relationship of land, sea and sky, as well as the realisation that most archaeologists were poorly equipped to interpret it.

The second event was the opportunity to use this data within one of the earlier archaeological applications of GIS in Europe. Opening such a digital box of sweets was a formative event, perhaps specifically with respect to the application of viewsheds. Truth to tell, I initially regarded such modules largely as an aid to analysing the functionality of Hellenic watchtowers. The larger relevance of such analyses to a landscape that I increasingly understood as visually integrated took some time to blossom. Consequently, for two years I assiduously recorded, on paper, all I could see from every hillfort and tumulus I visited. However, digital applications of the edge of sight and the interface with the sky increasingly informed my later work. The generation of tens of thousands of viewsheds within the Stonehenge landscape, more than 20 years ago, provided me with a greater appreciation of the pervasive role of horizons, and by implication the sky, to structure the archaeological landscape at a fundamental level (Exon et al.2000).

Retrospectively, I have no doubt that many early applications using GIS may well be considered naïve, and relatively few GIS practitioners at the time would have seen, fully, the potential linkage of their work with those undertaking archaeoastronomy in the strictest sense. The identification of horizons as a common interest to both camps might well have driven an agenda for a disciplinary study of the sky - but it did not. What was equally significant, was that many of those archaeologists applying GIS with reference to the sky/land interface often framed their observations in an imbued manner. Consequently, they were more likely to associate their output with those of a phenomenological turn. Unfortunately, such approaches were sometimes regarded with a degree of antipathy and by others as an abstract commodification of social space rather than an aid to interpretation. The opportunity for productive engagement was not realised during this time and, to an extent, this situation has never been fully resolved.

Other, fundamental barriers have affected the manner in which some archaeologists have been allowed to perceive the sky within studies of the past. In Britain, at least, there 
has been a presumption that the sky has been important primarily in relation to the study of sedentary societies. The lack of monuments with obvious astronomic alignments prior to the onset of farming, the loss of significant aspects of material culture over time, particularly organic objects, aligned with entrenched sentiments within necessarily strong traditions of chronological and environmental studies, have imposed a subaltern position on earlier societies. In such a situation, a proper appreciation of the heavens was unlikely to prosper. There is, happily, an increased understanding of the temporal depth of evidence for the observation of the sky within the archaeological record and, perhaps, an awareness that the extremes of monumentality are not the sum of all behaviour in respect of the study of land and sky. However, such developments still have some way to go. A generational shift may still be still required to fully relinquish some of these historical shackles.

Ultimately, looking at the Sun has always been a dangerous occupation, whether the consequence of a dearth of technical capacity, the iniquities of theoretical positioning or the lack of a comprehensive structure that might constitute a proper study of sky. Having made such an observation, I would suggest that our ultimate failing has been the result of intellectual selfishness and an inability, or unwillingness, to provide equal access to the sky throughout our disciplines. From the arcane to the aesthetic, there was not a time that past societies did not consider the firmament, and, whether interpreted through the cloud, or thick description, we should always lift our eyes to the heavens.

\section{References}

Bradley, R., 1998. The Significance of Monuments. London: Routledge.

Baudelaire, C. P., 2006 [1861]. "Les plaintes d'un Icare". In Les fleurs du mal by C. P. Baudelaire, 237. Edited by J. Dupont (updated edition). Paris: Flammarion.

Exon, S., V. Gaffney, A. Woodward and R. Yorston, 2000. Stonehenge Landscapes: Journeys Through Real-andImagined Worlds. Oxford: Archaeopress.

MacKie, E. W., 1974. "Archaeological Tests on Supposed Prehistoric Astronomical Sites in Scotland". Philosophical Transactions of the Royal Society of London A 276: 169-194. https://doi.org/10.1098/rsta.1974.0018 